http://dx.doi.org/10.12795/PH.1992.v07.i01.03

\title{
JACINTO GRAU Y KAREL CAPEK. ACERCAMIENTO A UNA RELACION TEATRAL
}

\author{
José María Fernández Vázquez
}

Jacinto Grau is a strange dramatist in our literary history. Spurned by the commercial theatre of his time, experts have come to terms with his work with some reservations. However, in the 1920's, he became a well represented author of renom in the theatres of Europe.

Karel Capek, also a playwright brought his plays to the public in Prague. Both of them, together with Pirandello were united in representing the human problems of domination and creation. His plays, R.U.R. (Capek) and Elseñor de Pigmulion (Grau), written in the same year were included in the programmes of the most fashionable of the European theatres.

La historia de nuestra literatura se escribe en la mayoría de los casos partiendo de los mismos reconocimientos y desde los mismos olvidos. Entre ambas posiciones, se encuentran las mismas anécdotas. Estos casos curiosos se repiten en gran parte de los manuales y estudios generales de literatura de un modo parecido sin buscar mayor explicación a los hechos que se citan. Son como los afluentes conocidos de un gran río a los que rara vez prestamos más atención de la supuestamente debida.

Jacinto Grau constituye toda una anécdota en nuestra historia literaria. Este dramaturgo catalán intenta renovar la escena y crear un teatro de gran calidad ajeno y alejado del que se estrenaba en el primer tercio de siglo. Su producción teatral comienza en el año 1902 y acaba en el año 1958, pero sus grandes obras se escriben entre los años diez y treinta. Es significativo que un gran conocedor del teatro de la época como es Luciano 
García Lorenzo' incluya a este autor en la corriente del teatro intelectual junto con Unamuno, Azorín y, más alejado cronológicamente, con Ramón Gómez de la Serna.

Estos dramaturgos aspiraron a una renovación de la escena española de su tiempo. No fueron los únicos innovadores y sus intentos se cuentan más por fracasos que por éxitos. Sus obras difícilmente se estrenaban y la mayoría de ellas, salvo raras excepciones, no obtenían el favor del público. El teatro que escribían estos autores eran piezas innovadoras en el lenguaje y en la forma, sin concesiones al público, fundamentalmente farsas o tragedias, géneros poco apreciados en un momento más receptivo con los dramas o melodramas; en definitiva, un teatro difícil con pretensiones de calidad aunque a veces olvidara las mínimas normas dramáticas. Estas obras se escriben desde posicionamientos intelectuales o afirmaciones anteriores a las mismas. De ahí que Jacinto Grau prologue sus obras en un intento de aclararlas, hacerlas comprensibles y justificar su fracaso en muchas ocasiones.

La unión literaria de Grau con Unamuno y Azorín no es errónea. Grau dehe mucho a Unamuno a quien conocía y trataba con gran respeto y admiración, dedicándole uno de sus pocos intentos ajenos a la dramaturgia, el ensayo Unamuno y la España de su tiempo. Sin embargo, pensamos que esta unión no ha favorecido su consideración crítica. Azorín y Unamuno poscían una producción novelística y ensayística importante que facilitaba un posible perdón y compresión hacía un teatro propio de intelectuales, pero que se distanciaba totalmente de la realidad escénica. Las innovaciones de Valle-Inclán eran propias de un bohemio genial como el autor gallego, quien renunció a ver sus obras sobre la escena. El teatro expresionista y simbólico de RAMON era el único posible en Gómez de la Serna. Jacinto Grau en este sentido se asemeja al hermano feo y pobre de una familia agraciada. El teatro, una novela El dominio del mundo, publicada en Madrid, en «La Novela Mundial» el año 1927, y escasos ensayos, la mayoría de ellos consagrados al teatro, constituyen toda la producción literaria de Grau. Sin embargo, Jacinto Grau dominaba la técnica teatral, conocía el teatro europeo de su momento y escribió grandes obras, algunas como El Señor de Pignialión, dignas de incluirse, por derecho propio, entre las mejores del teatro español contemporáneo.

«Estrena Grau, teatro cerrau», o «Grau, Grau, teatro cerrau» son al gunos de los tópicos que circulaban en los corrillos teatrales acerca de la oscuridad y el fracaso de los dramas de Grau. Estos dichos tendrían que herir profundamente la sensibilidad de una persona orgullosa, convencida de la bondad de lo que hacía, con un carácter áspero y que atacaba sin contemplaciones a empresarios, actores, público y crítica por no comprender el alcance de su obra. Contrariamente al rechazo que el teatro de Grau soportaba en el interior de España, sus obras eran apreciadas más allá de nuestras fronteras. El respeto fucra del país y, una vez. visto el éxito europeo, un sentimiento confuso dentro del mismo entre la admiración y la indiferencia son la base de lo que se dio en llamar «el caso Grau».

I L. Garcia Lortin/o, El teatro español hoy (Barcelona 1975). 
Sin lugar a dudas, el punto culminante de la azarosa vida teatral del autor catalán que tenía fama de jettatore lo supone El Señor de Pigmalión, no sólo literariamente, sino también escénicamente, una obra que como ha dicho bellamente García Lorenzo «el público español aplaudió, reconociendo sus muchos valores cuando ya en los círculos teatrales europeos sc había hablado mucho de ella, cuando ya el público de París, Praga y Roma había dado el visto bueno, cuando Dullin, los hermanos Kapec y Pirandello habían sellado el visado de vuelta para el país en que había nacido»².

El Señor de Pigmalión se escribe en 1921, el mismo año que Pirandello redacta Seis personajes en busca de un autor y Karel Capck su obra R.U.R.. Es necesario admitir, por mera lógica cronológica, que entre estos autores no hubo influencias a la hora de componer sus obras. Las tres escenifican, lejos de cualquier semejanza con el teatro realista, el problema del hombre, su creación, su independencia, desde posturas diversas y con tramas diferenciadas entre sí. La posible conexión, siempre a posteriori, entre Grau y Pirandello la niega Chicharro de León quien afirma que Grau «nada pide prestado a Pirandello» ${ }^{3}$. García Lorenzo en la introducción al Teatro Selecto de Jacinto Grau también considera que la relación con Pirandello es escasa, aunque sus puntos de contacto son evidentes como es el tema del teatro en el teatro, y destaca como más decisiva la relación con la obra de Unamuno, Niebla; en esta, es el ente creado Augusto Pérez quien muere en lugar del creador, como en la farsa de Grau. Las posibles relaciones del autor español y el autor checo las señalaremos más adelante.

Si las obras de Grau tenían poca resonancia una vez publicadas en España, eran traducidas con relativa celeridad a otros idiomas. Francia fue uno de los primeros países en celebrar la capacidad de Grau. Así Jean Cassou le dedica su atención en Mercure de France en 1922 y Francis de Miomandre se decide a traducirlo. Sus obras eran leídas en Ios cenáculos literarios más importantes del momento de la capital parisina como la tertulia literaria que se congregaba en la casa de la Condesa de Clermont Tonnerre. En esta tertulia, Miomandre dio a conocer El conde Alarcos, obra que primeramente iba a representar Dullin. Finalmente, el propio Miomandre le ofreció El Señor de Pigmalión a Dullin quien la prefirió para su montaje. Así se estrena el 16 de febrero de $1923 \mathrm{en} \mathrm{cl} \mathrm{teatro}$ L'Atelier siendo su director Charles Dullin c interpretando el papel de Pedro de Urdemalas Antonin Artaud.

Tras el triunlo en París la estrenan en Praga los hermanos Capek ${ }^{4}$. Esta vez no la acoge una sala de tendencias experimentales como era el local de Montmatre. El Teatro Nacional de Praga, en esos momentos unas de las escenas más prestigiosas de Europa, recibe la obra española, la primera obra hispana contemporánea que se representaba en Checoslovaquia. El director del teatro Karel Capek debió sentirse atraido por una farsa

2 L. Garcia LoRr-Næo), «Introducción», en J. GRAU, Teatro selecto (Madrid 1971). En esta edición leo El Señor de Pigmalión.

3 J. ChCIARROI) LI:ON, «Pirandellismo en la Iiteratura española», en Quaderni ibero-americani 15 (19.54) 406-414,

4 R. BAI:/A, "El Señor de Pigmalion en Praga», La Esfera 623 (12-12-1925). 
que indudablemente le evocaría a sus robots de R.U.R., obra estrenada en Praga el 26 de enero de 1921 y que se dio a conocer en Londres en 1923 y en París en 1924. Las posibles conexiones entre ambas piezas ya fueron señaladas por Díez-Canedo con motivo del estreno español de la obra de Grau'. El 3 de septiembre de 1925 se estrena en Praga El Señor de Pigmalión, los papeles principales corren a cargo de los actores Cáclav Vydra y Jarmila Kronbauerova. La escenografía cargada de referencias expresionistas la proyectó Josef Capek, pintor y escritor, en colaboración con su hermano Karel; la musica la compusó Podasevsky. El éxito de la obra fue impresionante, montándose a continuación en la capital bohemia otros dramas de Grau como El conde Alarcos. El reconocimiento de Grau fue total en distintos países europeos como Alemania, Holanda, Polonia, la península Escandinava etc. En el año 1926, Pirandello la incluye en el programa de su teatro de Arte.

El 18 de Mayo de 1928, cinco años después de su estreno en París, el teatro Cómico de Madrid la representa. Son sus actores principales Pepita Meliá y Benito Cibrián, acompañados por Oltra Venegas y Llórens, entre otros. La escenografía la ideó con gran acierto Bartolozzi, también de tendencia expresionista. Sin embargo, parte de la crítica no la acogió con entusiasmo como Florido $r^{6}$ o Jorge de la Cueva ${ }^{7}$, quienes incluso restaron importancia al éxito que, según Enrique Díez-Canedo", obtuvo.

Si la pieza de Grau ha sido vista a la luz de la obra de Pirandello, no hemos encontrado ningún escrito específico acerca de las relaciones que puede tener con la pieza centroeuropea. La figura de Karel Capek se nos presenta como la figura de un hombre poseedor de un mundo interior inquieto que se contrarresta con una vida tranquila y sosegada, dedicado a la literatura, al periodismo y al Teatro Nacional de Praga. Un padre médico y una madre sensible permitieron que los hijos de la familia se dedicaran a actividades artísticas y al estudio. Accede a la universidad para estudiar filosofía, primero en Praga, para marchar posteriormente a Berlín y a París. De ambas estancias en el extranjero vuelve con conocimientos del teatro alemán del momento, de carácter expresionista, y de la poesía francesa, siendo uno de los primeros traductores de poetas franceses al checo. La obra de Capek, novelística y dramaturgia ocupan toda su producción, tiene como centro al hombre, previniéndole de los peligros de una sociedad mecanicista y materialista; critica la inmoralidad de la sociedad burguesa y defiende las posturas democráticas, siendo amigo personal del presidente Jan Masaryk. Capek se nos presenta como un hombre activo, conocedor del teatro europeo de su tiempo y lleno de todo tipo de inquietudes lo que le impulsó a viajar por varios países europeos entre ellos España. Fruto de este viaje es Viaje a España, publicado en Praga en $1930^{9}$ donde ofrece una visión tierna, apasionada y amorosa de nuestro país, llena por momento de recurrencias

\footnotetext{
E. Difz-Canis:o, «El Señor de Pigmalión de Jacinto Grau», El Sol (sábado 19-5-1928) 9.

FLORIDOR, «El Señor de Pigmalión», ABC (19-5-1928) 43.

J. Cunva DH L.A, «El Señor de Pignalión», El debate (19-5-1928) 4.

E. DIF:-CANDI:(0, 1928:9.

Existe un traducción en Hiperión (1989) realizada por JANA STANCHi. y Ci.ara Janés.
} 
tópicas y alejada de ellos en otras ocasiones. Creemos que no es casual que Capek estrenara a Grau, no sólo por afinidades en la obra, sino por cierto interés, de índole romántica tal vez, que España despertaba en el autor checo.

No somos partidarios de reducir las obras literarias a una sinopsis, pero en esta ocasión consideramos que es necesario hacerlo, al ser ambas obras poco conocidas hoy. Para evitar posibles malentendidos posteriores en la explicación empezaremos con la obra de Grau.

Pigmalión es un hombre de teatro, director de una compañía teatral muy especial, pues sus actores son muñecos que él mismo ha fabricado. Su compañía es contratada para actuar en el teatro del duque de Aldurcara quien lo tiene alquilado a unos empresarios que se muestran en la obra como embrutecidos e interesados únicamente por la rentabilidad de las representaciones, y acostumbrados a negociar con actores de mala calidad que se creen auténticos genios de la escena. Pigmalión enseña sus muñecos que se asemejan en casi todo a los humanos. Cada uno de los muñecos representa a un tipo de persona y están caracterizados como arquetipos populares españoles, el Tío Paco, Pedro Urdemalas etc. El duque se enamora de Pomponina, una muñeca bellísima y huye con ella. Los restantes muñecos, que odian a su creador aprovechan la salida abierta por el duque para escapar. Pigmalión enfurecido por la fuga sale en su busca y los encuentra en la casa de un peón caminero cuando habían hecho prisionero al duque. Pigmalión libera al duque y a su amante, quien lo había seguido en un ataque de celos. Pigmalión y sus muñecos se enfrentan, obligándoles el primero a seguirle; los muñecos se niegan y Pedro Urdemalas le dispara, dejándole malherido y huyendo a continuación. Finalmente, Pigmalión creyéndose seguro pide auxilio, pero Juan el Tonto, tipo bobo y rudo que no se había marchado, lo remata.

El título de R.U.R., la pieza de Karel Capek, se forma con las siglas de la compañía Robots Universales Rossum que tiene su fábrica en una isla. A esta isla llega, Elena, mujer humanitaria e hija de un prestigioso científico que va a interceder en nombre de la Liga de la Humanidad ante los directivos de la fábrica en favor de los robots. Elena se casa con el director de la fábrica y se queda a vivir en la isla. Transcurren cinco años, y los robots empiezan a sufrir cambios de conducta inesperados. Por otra parte, todo el mundo pide robots que se convierten en obreros y también en soldados. De repente, se conoce la existencia de una revuelta de los robots que va exterminando a la humanidad. Los fabricantes no pueden detener la producción pues los accionistas de la compañía sólo buscan beneficios y los presionan. La sublevación se extiende por todo el mundo hasta aniquilar a los hombres, sólo quedan con vida sus creadores a los que también se enfrentan. Los técnicos de la fábrica no se explican qué ha sucedido para que los robots se independizaran. Elena se acusa de haber convencido a unos de los técnicos para realizar transformaciones en los robots para darles un alma. Los robots aniquilan a todos los técnicos salvo a uno, Alquist, que debe fabricar más, pero este ingeniero no sabe. Desesperanzado, Alquist piensa que es el fin del mundo hasta que descubre a dos robots iniciando un rudo juego amoroso, a quienes bautiza como el nuevo Adán y la nueva Eva.

Ambas obras se conectan entre sí temáticamente, aunque las tramas desarrollen aspectos de difícil enlace. El problema de la creación del hombre por su igual, el hombre 
creador a semejanza de los dioses o de Dios y el consiguiente castigo por tal acto de soberbia fundamenta estas obras. El expresionismo se muestra en la raíz de estas piezas. El hombre alienado y su drama en una sociedad cada vez más mecanizada que oculta las verdaderas esencias del ser humano, es el tema preferido por los dramaturgos expresionistas alemanes que Capek conocería tras su estancia curopea, y de los que Grau también tendría noticia. La preocupación por el hombre nuevo se percibe en estos dramas.

De la tríada de piezas teatrales que se escribieron en 1921 con el tema del hombre creado, Seis personajes en busca de un autor de Pirandello es la que alcanza mayor éxito y renombre. Sin embargo, pensamos que las obras que comentamos han sido injustamente olvidadas a pesar de ser radicalmente modernas, y al menos tan innovadoras como la obra del maestro italiano.

El tema del nuevo Prometeo no es original; los románticos se preocuparon por él en varias ocasiones y la novela de Mary Shelley Frankenstein es el ejemplo mil veces citado, aunque destaque más su carácter gótico. De igual manera, no es nueva la preocupación del escritor frente a su personaje. Esta postura dialéctica la encontramos ya en Cervantes con Don Quijote, en Goethe El aprendiz de hechicero, en Unamuno Niebla, entre otros. Son creaciones literarias de «espejos», donde hay un doble sentido del arte como reflejo de la realidad y del personaje como reflejo del autor.

Sin embargo, las piezas teatrales que estudiamos se relacionan, no sólo como reflejos de la sociedad o del autor, o como obras de temática prometeica, sino también como configuración de una nueva sociedad distinta a la actual. Esto nos evoca la idea de utopía. Es sin duda la obra de Capek la que nos parece más utópica. Contiene todos los elementos que según Trousson ${ }^{10}$, definen generalmente las utopías literarias, es una narración, no un tratado, refleja una comunidad organizada socialmente y se sitúa en un espacio insular, además se realiza un viaje iniciático. Sin embargo, no es un mundo de realidades perfectas lo que nos presenta Capek. Se trata una utopía satírico-científica donde nos previene de los excesos del mundo mecanicista y materialista, critica la fabricación de armas de guerra y advierte de los peligros de la igualación del hombre por parte del Estado. Así los robots, que tienen la misma cara, proclaman el lema modificado de la ideología comunista «Robots del mundo, uníos». Es importante esta referencia pues la obra se escribió a escasos años de la revolución soviética. La importancia de esta obra radica en su postura adelantada en muchos años a otras obras de lo que se ha dado en llamar distopía ${ }^{11}$. Representa un mundo condenado a sociedades deshumanizadas y dictatoriales como son las novelas de Huxley, Un mundo feliz o de Orwell, 1984, claras distopías angustiosas; los robots de Capek, quien creó y utilizó en la literatura por primera vez esta palabra, son antepasados directos de otros robots aniquiladores de la sociedad humana, como los de Asimov.

10 R. Trousson, Voyages aux pays de nulle part (Bruxelles 1987). Cilado por A. Porras Mr:Drano, «En torno al concepto de utopian, Discurso $3 / 4$ (1989) 157-167.

1 C. Gual. GarCía, «El «no lugar» de los antiguos griegos», Leer 41 (1991) 30-33. 
Las obras de Capek o de Grau no se escriben de un modo casual sino que son muestras de las inquietudes sociales de la Europa de posguerra. El Tratado de Versalles de 1918 no había buscado una paz que evitara situaciones tensas, sino que se planteó de modo revanchista y deseaba el hundimiento del imperio alemán. La paz era más una tregua. Junto a este espíritu político, la sociedad curopea descubría los horrores de una guerra en la que, por primera vez, se bombardearon poblaciones civiles y se utilizaron armas químicas. El hombre de la década de los veinte se sorprendía de la capacidad del ser humano para matarse de un modo masivo. Sentía el hombre desconfianza hacia el propio hombre, hacia los sistemas políticos que habían favorecido esa masacre, hacia los sistemas filosóficos alineantes. Especialmente, desconfiaba y se sentía atraído por la ciencia que había facilitado la matanza indiscrimada de la guerra y a la vez descubría múltiples posibilidades en un mundo futuro nuevo con las recientes teorías ciéntificas, como el relativismo de Einstein. Esta desconfianza del hombre hacia el hombre iba a permitir que, pocos años después, las teorías del hombre masa con su terrible ideología y consecuencias invadieran toda Europa, llevando a la Segunda Guerra Mundial.

Los artistas buscaron salidas a esa malestar y quiebra del sistema de valores. El cubismo, el surrealismo, el dadaismo, el expresionismo fueron muchas de las manifestaciones artísticas novedosas. El expresionismo encontró en el teatro su medio ideal. Una oposición radical al realismo; la búsqueda de tipos por medio de marionetas; la escenificación por cuadros, pero sin perder la unidad última del espéctaculo por medio de los elementos del montaje como luces, sonidos, decorados, son sus principales características. Como podemos observar, las obras de Capek y de Grau se pueden encuadrar en csta tendencia expresionista reflejo del desasosiego de la nueva época.

El expresionismo descubre en el cine muchas posibilidades, realizándose películas que se pueden considerar obras maestras. Entre estas podemos señalar El Golem de Wegener que trata también sobre el hombre creado en la figura de un monstruo de arcilla, o Metropolis de Fritz Lang, reflejo de la ciudad deshumanizada, del peligro del hombre masa que anuncia también Capek.

La obra de Capek es una de las primeras en denunciar los peligros de un mundo futuro dominado por las máquinas. Se desarrolla en una fecha incierta, aunque Capek cometa un error cronológico importante, pero que nos sitúa la acción en un futuro inconcreto, tal vez el siglo XXI. El director de la fábrica historiando la invención del hombre-maquina, de los humanoides, dice «esto ocurría en el año mil novecientos treinta y dos, exactamente cuatrocientos años después del descubrimiento de América» ${ }^{12}$. Los anacronismos cronológicos son evidentes, ni se descubrió américa en ningún año 32, ni en 1992, admitiendo un posible error de traducción o de impresión, se cumplen cuatrocientos años del descubrimiento americano. En cualquicr caso, es una fecha alejada del escrito de 1921. Es una obra de carácter futurista, una utopía negra y angustiosa de concepción

12 J. y K. CAPl:K, R.U.R. y El juego de los insectos (Madrid 1966) 18. KaRH escribió con su hermano Jos:F la obra El juego de los insectos. 
netamente expresionista, aunque al final, en las palabras del último humano, Alquist, se vislumbra una posibilidad de esperanza para un nuevo hombre.

La obra de Grau nace comprometida con el momento histórico de su autor y con la problématica del teatro español. La jornada I con la que se abre la farsa refleja perfectamente un mundo teatral dominado por empresarios insensibles y avaros, un público embrutecido, autores pendientes de sus derechos económicos, pero ajenos a cualquier intención artística. Por último, caricaturiza a los actores dominados por su soberbia y confiados siempre en un arte que no poseen. Pigmalión es un constructor de muñecos ideados para representar farsas mejor que los actores profesionales. Inmediatamente, un hombre innovador del arte dramático de principios de siglo se nos materializa, es Gordon Craig. Craig pedía la supresión del actor para lograr la auténtica reforma teatral. No quiere un actor sentimental, pide que el sustituto de estos sean las supermarionetas, un actor que cree en la escena no que imite sobre la misma. Los muñecos de Pigmalión son auténticas super-marionetas, muñecos dotados con capacidades humanas. La farsa grauniana es la manifestación en la escena de la ideas de Gordon Craig como ningún autor había sido capaz de representarla. La importancia de la pieza de Grau podría radicar solamente en la plasmación de estas ideas.

Sin embargo, la obra del autor catalán no acaba en la modernidad de su montaje. Las marionetas representan tipos populares españoles. Cada uno de ellos poseen las cualidades y defectos que se les suponen a los hombres que representan. El hombre con sus mezquindades y sus odios es la farsa que los muñecos cuando están solos escenifican. El muñeco no puede escapar del papel para el que está construido; igualmente, el hombre no escapa de su condición en ningún momento de su vida.

El tema de la creación de seres parecidos al hombre, manlike, auténtico engarce entre las dos obras, se presenta en cada una de ellas de distinto modo. Los muñecos de Grau tienen cualidades humanas desde un principio, pueden hablar, pensar, sentir, no son ajenos al hombre. Pigmalión se configura como un Prometeo, semejante a los dioses, les iba a robar su secreto de la vida, crearía muñecos aún más perfectos que los hombres y sus objetos se rebelan contra el creador pues no les da libertad sino que los mantiene como esclavos, dependiendo en todo momento de él. Los muñecos cansados se rebelan y toman la libertad, supremo bien, que su creador les niega, no importándoles acabar con él para conseguir su propósito. Pigmalión se asemeja a un dios pues crea a todos los muñecos de un modo diferente y con personalidad, es un auténtico creador; aunque en una última ironía, a Pigmalión no le mate ningún dios, sino el muñeco más imperfecto y bobo, Juan el tonto. Si los muñecos a solas en el acto II representan la farsa del hombre atrapado por los instintos del hombre, Pigmalión y sus muñecos representan en el acto III la farsa del hombre dominado y dependiente de un poder superior y tiránico que se configura como tragedia y termina siempre con la aniquilación de uno de los dos contricantes, en este caso se acaba con el dominador al final de la obra. Grau rencoroso no puede dejar de representar otra farsa, la farsa del teatro que escenifican Pigmalión, el duque y los empresarios. Tres farsas independientes e íntimamente entrelazadas constituyen una de las obras más importante de nuestro teatro. 
La pieza de Capek trata de un modo diferente el acto de la creación. En esta pieza, los robots se asemejan mucho al hombre, pero no se igualan nunca con él como en el caso español. El acto de la creación no es individual, sino colectivo. El hombre-masa alienado y seguidor de una élite de carácter dictatorial es denunciado con esta actitud. El robot tenía que sustituir al hombre en tareas rudas en una sociedad perfecta y futura. Sin embargo, el cambio de los robots se produce cuando se equiparan al hombre, cuando se les quiere dar la esencia del hombre como es el alma. En la revuelta de los robots estos acceden al poder y aniquilan al hombre, pero no pueden autorreproducirse, necesitan aún del ser humano. Al final, descubierta la pareja más parecida a los hombres, pues eran unos robots de experimentación secreta que ya poseen sentimientos, el ingeniero evoca, como Pigmalión, a Dios para pedir perdón por querer sustituirlo. Pigmalión es un rebelde y como tal, sufre el castigo de los dioses; los hombres de Capek son víctimas, pero tienen una esperanza última de salvar o de crear una nueva Humanidad en esa pareja, sin nada de lo que ha producido la exterminación de la antigua Humanidad. Como en el film de Lang, la esperanza se materializa. Grau es mucho más duro, al no permitir ninguna salida; el nuevo hombre por Pigmalión creado es tan terrible como su creador.

Ambas piezas se muestran muy interesantes, y recogen el grado de inquietud que despertaban en la década de los veinte los adelantos científicos, la materialización de las nuevas sociedades que proponían el fascismo y el comunismo, y el anhelo de búsqueda de las esencias humanas. Las dos obras se descubren radicalmente modernas en su forma, la checa muy próxima al expresionismo, y la española perfectamente adaptable a este movimiento y cercana a las teorías más innovadoras de la escena. También estas obras tienen una clara vocación globalizadora, la pieza de Capek se muestra más universalista, está más cercana a los cambios que se producen en los distintos países. Sus ideas utópicas, o mejor distópicas, serán rápidamente aceptadas especialmente en países de habla inglesa donde tuvo Capek más proyección. La obra de Grau se configura de un modo más universal desde una concepción totalmente hispana, sus personajes representan al hombre, sus impulsos y sentimientos de un modo global. R.U.R. y El Señor de Pigmalión tienen evidentes contactos y diferencias, pero no son desconocidas una de otra. Estas obras deben ocupar, por derecho propio, un lugar importante en la literatura universal, hijas dignas y conscientes de su momento histórico. 